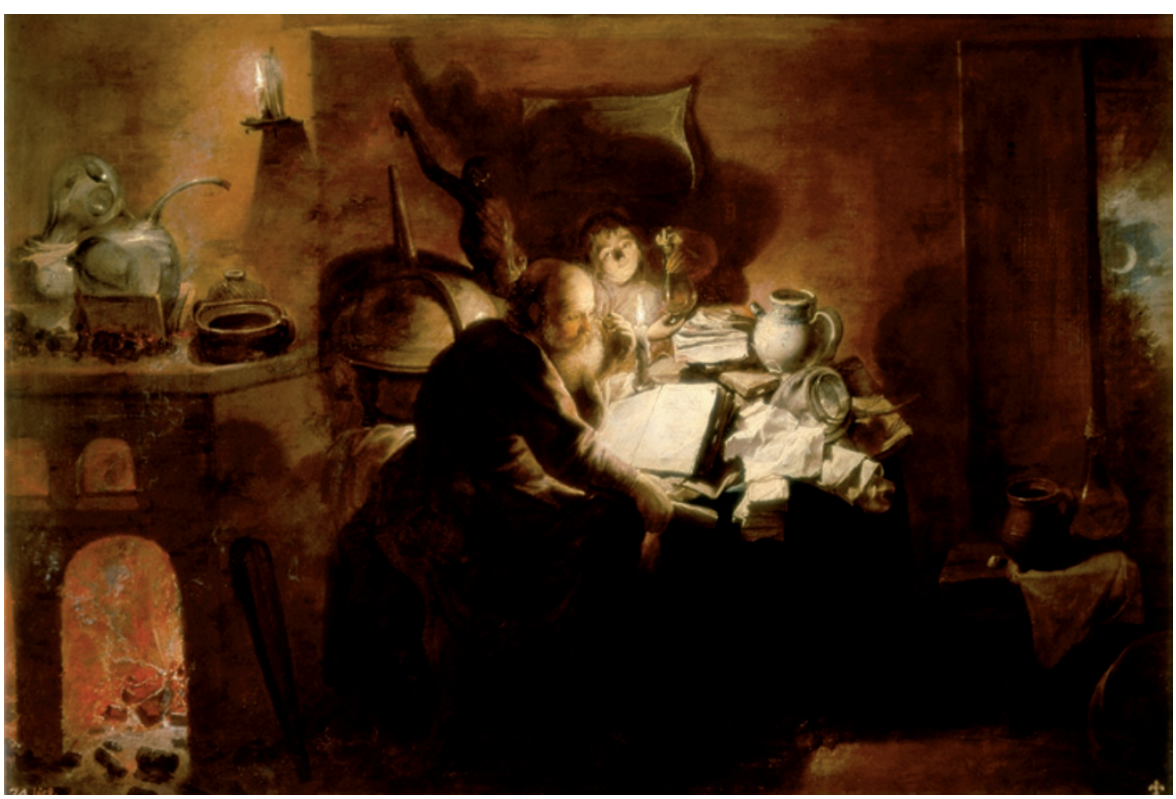

The Alchemist (1640) by David Ryckaert III shows a practitioner at work.

\title{
HISTORY
}

\section{Realms of gold}

\section{Jennifer Rampling relishes a masterful take on the age-old allure of alchemy.}

A round 1680, Robert Boyle, author of The Sceptical Chymist (1660), described meeting a stranger who demonstrated an unusual experiment. Tipping some ruby-coloured powder onto the blade of a knife, he cast it into a crucible of molten lead. The lead congealed into "very yellow" metal, which Boyle's tests proved in his estimation - to be pure gold.

Boyle's account, retold by Lawrence Principe, drives home a problem facing all scholars of alchemy: why, across the ages, have so many intelligent people been convinced by the promise of metallic transmutation? The Secrets of Alchemy comes closer than any other single work to explaining the grounds - rational and empirical, as well as religious and wishful - for alchemy's longevity.

Principe's delightful writing style brings to life a depth of learning matched by few in the field. This expertise, coupled with the author's determination to strip his topic of anachronism, sets The Secrets of Alchemy apart from the usual introductory tome. After comments on alchemy's lingering popular appeal (think Harry Potter and Fullmetal Alchemist), Principe engages with the misconceptions that have long dogged his subject, particularly its association with magic, mysticism and quackery. A key premise of the book is that these are often modern associations. To understand how alchemy 'worked' for its practitioners, we must meet them on their own terms.

Principe traces the theory, practice and context of alchemy from its origins in Egypt in the first few centuries AD to its development and maturity in the medieval Islamic lands and Latin Europe. He then engages with Enlightenment critiques of transmutation, tracing their consequences

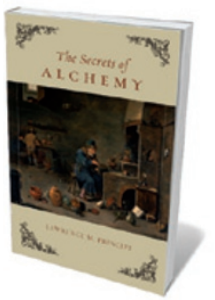

The Secrets of Alchemy LAWRENCE M. PRINCIPE University of Chicago Press: 2012. 296 pp. $\$ 25, £ 16$ up to today before returning to alchemy's "Golden Age" in Renaissance Europe.

Some will recognize elements from Principe's earlier work: the argument that 'alchemy' and 'chemistry' overlapped in the early modern world (and so should be referred to simply as 'chymistry'); his concern that Enlightenment polemics and nineteenth-century fads have distorted alchemy's modern reception; and his view that even the alchemists' most outrageous allegories may disguise genuine chemical effects. In sum, he does not believe that alchemists made gold, but does show that they were serious in the attempt.

Like Boyle, Principe recognizes that sceptics will be convinced only by displays of incontrovertible expertise. The book is at its most fascinating when Principe reveals glimpses of his own skill. A chemist as well as a historian, he has recreated a range of alchemical experiments, revealing the practical foundations of seemingly opaque alchemical instructions. The first chapter opens with a recipe from one of the earliest surviving metallurgical treatises, the third-century Leiden Papyrus. The process can be easily replicated, producing a golden patina on a silver ingot. And if Principe's photographic evidence does not convince, an endnote gives instructions on how to do it yourself.

Yet if alchemists engaged in 'real' chemistry, why did they disguise their methods in such baffling ways? In one sequence, Basil Valentine - a fictitious name assigned to a number of alchemical treatises - describes how a king is devoured by a wolf, but resurrected after the creature is cast into a fire. This exotic conceit evolved from an earlier tradition of alchemical secrecy. It also reflects a wider contemporary passion for emblematics - the encoding of meaning in playful images, mottoes and verses.

Such puzzles were designed to be solved. As Principe demonstrates, Valentine's wolfish encounter is an allegory for the technique of purging gold using antimony ore, "the ravenous grey wolf". This process culminates with the volatilization of gold. Difficult enough to achieve in modern labs, this was an astonishing technical feat for early practitioners, who were hampered by impure ingredients, non-standard apparatus and an absence of thermometry. Boyle also cracked Valentine's puzzle, remarking that although difficult, "it eventually succeeded beautifully".

So was Boyle a scientist, alchemist, apologist or interpreter? For that matter, how about Principe? As the book suggests, modern readers can profitably reflect on how they use such distinctions.

For, as Principe concludes, alchemy cannot simply be reduced to chemical procedures. Many practitioners subscribed to a widely held belief in the 'connectedness' of humans, God and nature. In this world view, analogy had demonstrative as well as illustrative power: similarity between small-scale and large-scale phenomena might offer clues to unseen laws of nature. Such correspondences strike us in alchemical writing, because they have disappeared from modern scientific discourse. The Secrets of Alchemy reminds that too-selective reading can mask the influence of such views on the past science we now accept as canonical. After Isaac Newton's Principia, why not browse his theology — or alchemy?

Jennifer Rampling is a Wellcome Trust Postdoctoral Research Fellow in the Department of History of Science, University of Cambridge, UK. e-mail:jmr82@hermes.cam.ac.uk 